\title{
IMPACT VISION SYSTEM ON ACROBATICS GYMNASTS’ BALANCE STABILITY
}

\author{
Nikolay Ivanov \\ National Sports Academy "Vassil Levski", Sofia, Bulgaria
}

\begin{abstract}
Acrobatics gymnastics is a discipline that is one of the best examples of the ability of human body to maintain balance. Therefore, the high level of balance stability of acrobatics gymnasts is very important in order to achieve high level of results in this sport. The aim of present study is to determine what is the impact of vision on acrobatics gymnasts' balance stability. Methods. 12 gymnast national level gymnasts (females) aged $15(S D \pm 3)$ were involved in this study. Validate force platform (Huurnink et al., 2013) "Nintendo Wii Balance board" (WBB) were used. The parameterization of center of pressure (CoP) trajectories changes, ellipse area, were measured. After individual warm up ten tests, 30 seconds each, plus two tests 10 seconds (twelve in total), were performed on a WBB. Compare analyze showed significant differences between COP EA (eyes open and eyes closed) tests. Individual tests showed up three to four times lower results, exception for test №7 and №8 (handstand). Conclusion: COP - Ellipse area increased with significant difference, average $26,53 \mathrm{~cm}^{\wedge} 2$ or $214 \%$ between eyes open and eyes closed tests. More than two times lower results of the balance stability without vision (eyes closed). Total path Len (TPL) also increased with significant difference, average 143,52 $\mathrm{cm}$. or 116\% between EO and EC tests. More than one times longer TPL, which confirm the results of COP EA also. Results of the present study is a starting point for further research in regard of the development of new accelerating methodologies of training in balance exercises in acrobatics gymnastics.
\end{abstract}

Key words: balance, stability, biomechanics, gymnastics, acrobatics

\section{INTRODUCTION}

Acrobatics gymnastics is a discipline that is one of the best examples of the ability of human body to maintain balance. Therefore, the high level of balance stability of acrobatics gymnasts is very important in order to achieve high level of results in this sport. The balance is one of main components of coordinative abilities has not been thoroughly investigated in acrobatics gymnastics. The researches is mainly directed at other gymnastics disciplines (artistic, rhythmic) (Gateva, 2016; Hedbavny et al., 2013; Vuillerme et al.,2001; Warren et al.,1988). From biomechanics point of view the balance stability depends on mutual location of CG (centre of gravity) and point of support. The main factors are distance between CG and point of support, the size of support area and etc. From physiological point of view depends of function of vestibular apparatus, visual system (eyesight), proprioception, central nervous system and motor units (Andonov et al.,2011; Gateva et al., 2015). As we know limitation of visual control (Gospodarski, 2016) considerably disrupted postural performance. That's why the importance of vision in balance stability need to be deeply investigated.

The aim of present study is to determine what is the impact of vision on acrobatics gymnasts' balance stability. The main task was to determine tests, indicators of measure and the duration of the tests; To process all dates; To compare and analyze the results.

\section{METHODS}

12 gymnast national level gymnasts (females) aged 15 ( SD \pm 3 ) were involved in this study. Validate force platform (Huurnink et al., 2013) "Nintendo Wii Balance board" (WBB) were used. The parameterization of centre of pressure $(\mathrm{CoP})$ trajectories changes were measured (recorded), ellipse area $\left(\mathrm{cm}^{\wedge} 2\right)$ based on displacement of center of gravity (CG) from the centre of WBB of frontal plane $\mathrm{X}$ $(\mathrm{L} / \mathrm{R})$ and sagittal $\mathrm{Y}(\mathrm{F} / \mathrm{B})$ were made it and total path Len of CG were measured. After individual warm up ten tests, 30 seconds each, plus two tests 10 seconds (twelve in total), were performed on a WBB. The following tests were performed: 


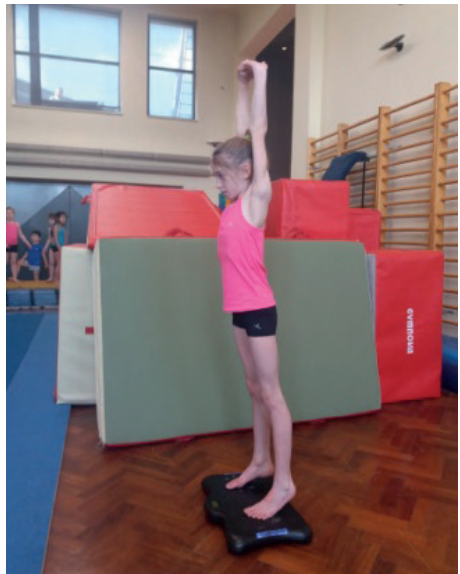

Figure 1. Test №1 with eyes open”

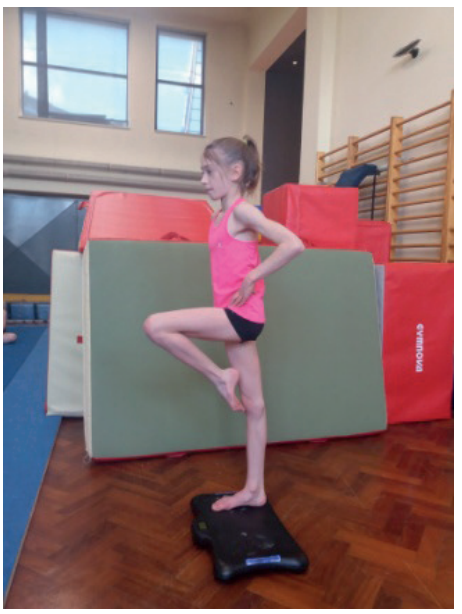

Figure 3. Test №3 EO, №4 EC”.

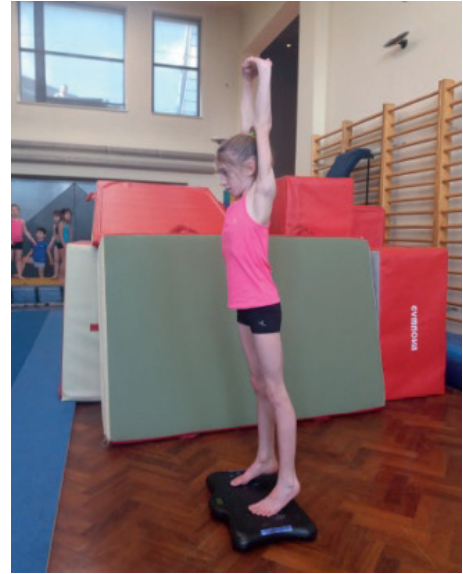

Figure 2. Test №2 eyes closed"

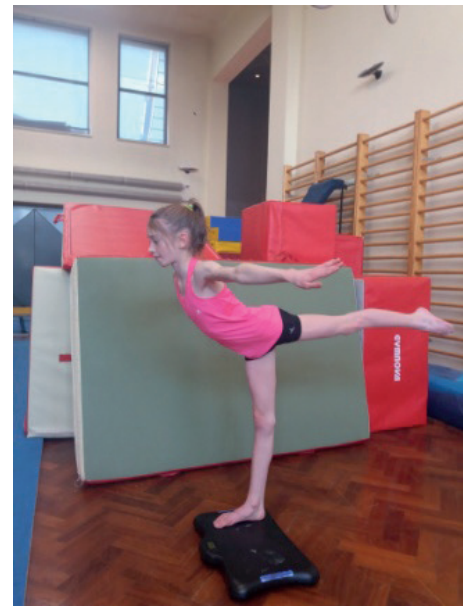

Figure 4. Test №5 EO, №6 EC”

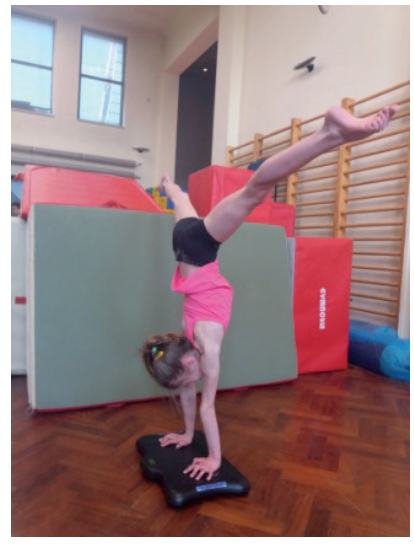

Figure 5. Test №7 EO,

№8 EC

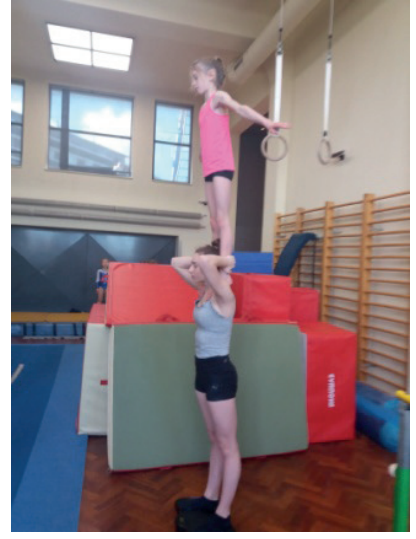

Figure 6. Test №9 EO,

№ 10 EC

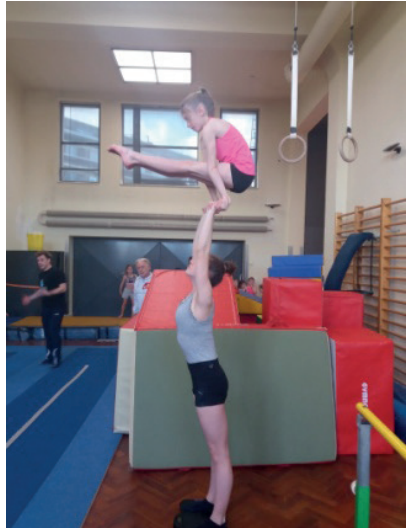

Figure 7. Test №11 EO,

№12 EC

\section{RESULTS AND DISCUSSION}

The COP ellipse area varied between $2,91 \mathrm{~cm} \wedge 2$ to $9,03 \mathrm{~cm} \wedge 2$ and total path Len of CG varied between $106,72 \mathrm{~cm}$. to $198,44 \mathrm{~cm}$. for test №1. The averages of test №1 is ellipse area (EA) $6,09 \mathrm{~cm}^{\wedge} 2$ and total path Len (TPL) $149,08 \mathrm{~cm}$. The same exercise, but eyes closed (Tests №2) ellipse area varied between 10,69 $\mathrm{cm}^{\wedge} 2$ to $95,76 \mathrm{~cm}^{\wedge} 2$ and TPL of CG varied between
$128,86 \mathrm{~cm}$. to $467,39 \mathrm{~cm}$. The averages results of test №2 is EA $30,04 \mathrm{~cm}^{\wedge} 2$ and TPL $289,05 \mathrm{~cm}$. EA varied between $4,09 \mathrm{~cm}^{\wedge} 2$ to $16,35 \mathrm{~cm}^{\wedge} 2$. TPL of CG varied between $108,41 \mathrm{~cm}$. to $161,95 \mathrm{~cm}$. for test №3. The averages of test №3 is ellipse area $7,64 \mathrm{~cm}^{\wedge} 2$ and total path Len $149,08 \mathrm{~cm}$. The same exercise, but eyes closed (Tests №4) EA varied between $7,14 \mathrm{~cm}^{\wedge} 2$ to $52,4 \mathrm{~cm}^{\wedge} 2$. and TPL of CG varied between 201,45 
$\mathrm{cm}$. to $519,57 \mathrm{~cm}$. The averages results of test №4 is EA $31,32 \mathrm{~cm}^{\wedge} 2$ and TPL $290,13 \mathrm{~cm}$. Test №5, EA varied between $5,59 \mathrm{~cm}^{\wedge} 2$ to $33,11 \mathrm{~cm}^{\wedge} 2$ and TPL of CG varied between $170,88 \mathrm{~cm}$. to $391,51 \mathrm{~cm}$. The averages results of test №5 is EA $17,9 \mathrm{~cm}^{\wedge} 2$ and TPL $252,48 \mathrm{~cm}$. The same exercise, but eyes closed (Tests №6) EA varied between $13,01 \mathrm{~cm}^{\wedge} 2$ to $148,24 \mathrm{~cm}^{\wedge} 2$ and TPL of CG varied between $191,64 \mathrm{~cm}$. to 577,01 $\mathrm{cm}$. The averages results of test №6 is EA $60,19 \mathrm{~cm}^{\wedge} 2$ and TPL $375,34 \mathrm{~cm}$. About test №7 only 7 people does 30 second held on handstand other 6 average is 21,5 seconds. However, ellipse area varied between 6,96 $\mathrm{cm}^{\wedge} 2$ to $72,92 \mathrm{~cm}^{\wedge} 2$ and total path Len of CG varied between $104,99 \mathrm{~cm}$. to $400,33 \mathrm{~cm}$. The averages results of test №7 is EA $31,76 \mathrm{~cm}^{\wedge} 2$ and TPL 218,85 $\mathrm{cm}$. In acrobatics gymnastics have a different position as "top", "base" and etc, which means a different level of skills about handstand are needed. The same exercise, but eyes closed (Tests №8) only one gymnast was able to perform 30 seconds on handstand with eyes closed. The average duration of handstand (eyes closed) is 10,55 seconds. Which show the importance of vision? Next four tests were performed by pairs. Ellipse area varied between $3,52 \mathrm{~cm}^{\wedge} 2$ to $34,30 \mathrm{~cm}^{\wedge} 2$ and total path Len of CG varied between $54,38 \mathrm{~cm}$. to $314,78 \mathrm{~cm}$. for test №9. The averages of test №9 is EA 13,68 $\mathrm{cm}^{\wedge} 2$ and TPL $141,41 \mathrm{~cm}$. The same exercise, but eyes closed (Tests №10) EA varied between $7,86 \mathrm{~cm}^{\wedge} 2$ to $73,32 \mathrm{~cm}^{\wedge} 2$ and TPL of CG varied between $107,38 \mathrm{~cm}$. to $492,53 \mathrm{~cm}$. The averages results of test №10 is EA $29,66 \mathrm{~cm}^{\wedge} 2$ and TPL $259,91 \mathrm{~cm}$. EA varied between $7,33 \mathrm{~cm}^{\wedge} 2$ to 28,16 $\mathrm{cm}^{\wedge} 2$ and TPL of CG varied between $52,51 \mathrm{~cm}$. to $119,1 \mathrm{~cm}$ for test №11. The averages of test №11 is EA $17,93 \mathrm{~cm}^{\wedge} 2$ and TPL $76,47 \mathrm{~cm}$. The same exercise, but eyes closed (Tests №12) EA varied between 15,14 $\mathrm{cm}^{\wedge} 2$ to $72,4 \mathrm{~cm}^{\wedge} 2$ and TPL of CG varied between $98,41 \mathrm{~cm}$. to $225,57 \mathrm{~cm}$. The averages results of test №12 is ellipse area $41,33 \mathrm{~cm}^{\wedge} 2$ and total path Len $158,13 \mathrm{~cm}$.

Table 1. COP EA

\begin{tabular}{|c|c|c|c|c|c|c|c|c|c|}
\hline \multicolumn{9}{|c|}{ COP ELIPSE AREA $-\mathrm{cm}^{\wedge} 2$} & \multirow{3}{*}{$d \%$} \\
\hline \multirow{2}{*}{ Tests } & \multirow{2}{*}{$\mathrm{n}$} & \multicolumn{2}{|c|}{ EYES OPEN } & \multicolumn{2}{|c|}{ EYES CLOSED } & \multirow{2}{*}{ d } & \multirow{2}{*}{$\mathbf{t}_{\mathrm{emp}}$} & \multirow[b]{2}{*}{$\mathbf{t}_{\mathbf{0 , 0 5}}$} & \\
\hline & & $\overline{\mathbf{X}}_{n}$ & $S_{H}$ & $\overline{\mathbf{X}}_{\mathrm{k}}$ & $\mathbf{S}_{\mathrm{k}}$ & & & & \\
\hline EA- №1 and №2 & 12 & 6,07 & 2,15 & 30,05 & 23,11 & 23,98 & 3,783 & 2,20 & 395 \\
\hline EA- №3 and №4 & 12 & 7,64 & 4,15 & 31,32 & 15,65 & 23,68 & 5,847 & 2,20 & 310 \\
\hline EA- №5 and №6 & 12 & 17,90 & 12,75 & 60,19 & 47,11 & 42,29 & 3,664 & 2,20 & 236 \\
\hline EA- №7 and №8 & 12 & 31,76 & 22,02 & 59,76 & 34,37 & 28,00 & 2,605 & 2,20 & 88 \\
\hline EA- №9 and №10 & 12 & 13,68 & 10,41 & 29,66 & 24,52 & 15,98 & 3,307 & 2,20 & 117 \\
\hline EA- №11 and №12 & 12 & 17,93 & 7,41 & 43,15 & 16,93 & 25,22 & 4,797 & 2,20 & 141 \\
\hline
\end{tabular}

Compare analyze (Table/1) showed significant differences between COP EA (eyes open and eyes closes) tests. Individual tests showed up three to four times lower results, exception for test №7 and №8 (handstand). However, as we mentioned earlier, this is due to the shorter duration of the handstand (Test №8, average- 10,55 seconds), even that
COP EA increase to $88 \mathrm{~d} \%$. The same situation with "pair's" tests (9 to 12), average $129 \mathrm{~d} \%$ increase COP EA with eyes closed. The average increment of COP EA for all tests is $214 \%$. Which means that more than two times lower results of balance stability without vision (eyes closed).

Table 2. TPL of CG

\begin{tabular}{|c|c|c|c|c|c|c|c|c|c|}
\hline \multicolumn{9}{|c|}{ TOTAL PATH LEN - cm. } & \multirow{3}{*}{$d \%$} \\
\hline \multirow{2}{*}{ Tests } & \multirow{2}{*}{$\mathbf{n}$} & \multicolumn{2}{|c|}{ eyes open } & \multicolumn{2}{|c|}{ eyes closed } & \multirow{2}{*}{ d } & \multirow{2}{*}{$\mathbf{t}_{\text {emp }}$} & \multirow[b]{2}{*}{$t_{0,05}$} & \\
\hline & & $\overline{\mathbf{X}}_{n}$ & $S_{n}$ & $\overline{\mathbf{X}}_{\mathrm{k}}$ & $\mathrm{S}_{\mathrm{k}}$ & & & & \\
\hline TPL- №1 and №2 & 12 & 149,80 & 39,87 & 289,06 & 91,37 & 139,26 & 6,929 & 2,20 & 93 \\
\hline TPL- №3 and №4 & 12 & 161,95 & 38,10 & 290,13 & 83,89 & 128,19 & 7,819 & 2,20 & 79 \\
\hline TPL- №5 and №6 & 12 & 252,48 & 84,66 & 375,34 & 124,22 & 122,85 & 7,053 & 2,20 & 49 \\
\hline TPL- №7 and №8 & 12 & 218,85 & 87,73 & 133,95 & 61,87 & $-84,90$ & 2,906 & 2,20 & -39 \\
\hline TPL- №9 and №10 & 12 & 141,41 & 91,13 & 259,91 & 144,45 & 118,50 & 3,591 & 2,20 & 84 \\
\hline TPL- №11 and №12 & 12 & 76,47 & 22,09 & 285,27 & 25,42 & 208,80 & 21,181 & 2,20 & 273 \\
\hline
\end{tabular}


Compare analyze (Table 2) showed significant differences between TPL (eyes open and eyes closes) tests. The results of tests №7 and №8 were in “opposite direction" (better with eyes closed) only. Because of duration of handstand (avr. 10,55 sec.). If we multipliable the results by three we will receive two times more TPL values. However, the average (without tests 7 and 8) of TPL is $143,52 \mathrm{~cm}$.

Gautier et al. (2007) analyzed the handstand performance on a stabilometric platform which recorded center of pressure (COP) in different conditions (eyes open, eyes closed and etc.). They are no significant differences between COP shift EO and EC. Our study showed significant difference between COP - ellipse area and total path Len- EO and EC in all tests were measured. We cannot compare, because of the different methods. However, we think exclusion of the vision seriously disturbs the balance stability of gymnasts. On the other hand, it enables the development of training methodology for balance exercise in acrobatics gymnastics.

\section{CONCLUSIONS}

1. COP - Ellipse area increased with significant difference, average $26,53 \mathrm{~cm}^{\wedge} 2$ or $214 \%$ between eyes open and eyes closed tests. More than two times lower results of the balance stability without vision (eyes closed).

2. Total path Len (TPL) also increased with significant difference, average $143,52 \mathrm{~cm}$. or $116 \%$ between EO and EC tests. More than one times longer TPL, which confirm the results of COP EA also.

3. Results of the present study is a starting point for further research in regard of the development of new accelerating methodologies of training in balance exercises in acrobatics gymnastics. Methodology should be based on the principle of "difficult condition trainings" and focused on improving other physiological systems (vestibular apparatus, proprioception, central nervous system and etc.), which are responsible for balance stability.

\section{REFERENCE}

Andonov, K., Hadzhiev, N., Kyuchukov, I. (2011). Biomechanics in gymnastics. NSA PRESS. // Хаджиев, Н., Андонов, К., Кючуков, И. (2011). Биомеханика в гимнстиката. НСА ПРЕС.

Gateva, M. (2016). Research on the balance stability of rhythmic gymnastics competitors. Research in Kinesiology, Vol.44, No1, pp.86-92.

Gateva, M., Gospodarski, N., Treneva, V., Avramov, D., Ivanov, N. \& Andonov, K. (2015). Comparison Between The Static Balance Of Practitioners From Different Sports and Non-Athletes. Edited by Radmann, A., E. Book of abstracts of the 20th Annual Congress of the European College of Sport Science. p. 569. Malmo, Sweden.

Gauthier, G., Thouvarecq, R. \& Chollet, D. (2007). Visual and postural control of an arbitrary posture: handstand. Journal of Sports Sciences, 25, pp. 1271-1278.

Gospodarski, N., Treneva, V. (2016). Study of the general and special vestibular stability of paddlers, age 12-18. Activities in physical education and sport, Vol.6, No.1, pp.102-106.

Hedbavny, P., Sklenarikova, J., Hubka, D., Kalichova, M. (2013). Balancing in handstand on the floor. Science of gymnastics Journal, Vol.5, Issue 3, pp.69-80.

Huurnink, A., Duncan P. Fransz, IdsartKingma, Jaap H. van Dieën. (2013). Comparison of a laboratory grade force platform with a Nintendo Wii Balance Board on measurement of postural control in single-leg stance balance tasks. Journal of Biomechanics, Volume 46, Issue 7, 26 April 2013, pp. 1392-1395.

Vuillerme, N., Danion, F., Marin, L., Boyadjian, A., Prieur, J.M., Waise, I. \& Nougier, V., (2001). The effect of expertise in gymnastics on postural control. Neuroscience Letters, 303, pp.83-86.

Warren, W.H. \& Hannon, D.J. (1988). Direction of self-motion is perceived from optic flow", Nature, 336, pp.583-585.

Corresponding author:

Nikolay Ivanov, Ph.D.

National Sports Academy "Vassil Levski" Studentski grad, Sofia 1700, Bulgaria E-mail: niki_acro@abv.bg 